\title{
Evidence for Silica Surface Three- and Five-Membered Metallacycle Intermediates in the Catalytic Cycle of Hydroaminoalkylation of Olefins Using Single-Ti-Metal Catalysts
}

Layal F. Yaacoub, Maha A. Aljuhani, Abdesslem Jedidi, Manal S. Al-Harbi, Walid Al Maksoud, Wiebke Wackerow, Edy Abou-Hamad, Jérémie D. A. Pelletier, Mohamad El Eter,* Luigi Cavallo,* and Jean-Marie Basset*

Cite This: https://dx.doi.org/10.1021/acs.organomet.0c00246

Read Online

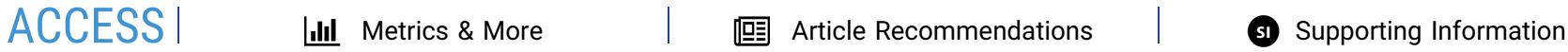

ABSTRACT: The single-site silica-supported group IV metal amido complex $\left[\mathrm{Ti}\left(\mathrm{NMe}_{2}\right)_{4}\right]$ gives the tris(amido)-supported fragment $\left[(\equiv \mathrm{Si}-\mathrm{O}-) \mathrm{Ti}\left(-\mathrm{NMe}_{2}\right)_{3}\right]$, which transforms into a three-membered metallacycle (called a metallaaziridine) by an $\alpha$ $\mathrm{H}$ transfer between two amido ligands. When the three-membered metallacycle reacts with 1-octene, it gives a five-membered metallacycle by insertion of the double bond into the $\mathrm{M}-\mathrm{C}$ bond of the metallaziridine. These two metallacycles, key intermediates in the catalytic cycle of the hydroaminoalkylation of terminal olefins, were isolated and fully characterized following the surface organometallic chemistry (SOMC) concept and procedures. This paper shows that surface organometallic chemistry can be used

to identify and fully characterize three- and five-membered metallacycles of $\mathrm{Ti}$ in the hydroaminoalkylation of olefins.

Tydroaminoalkylation, reported first by Maspero $^{1}$ and 1 then by Nugent, ${ }^{2}$ is a reaction described by the addition

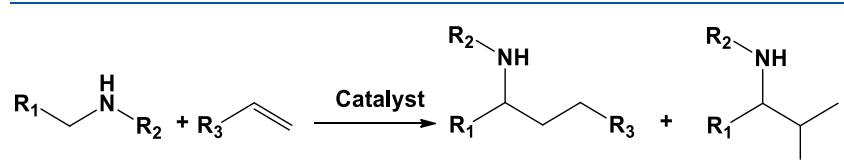

Figure 1. General reaction of hydroaminoalkylation according to Nugent. ${ }^{2}$

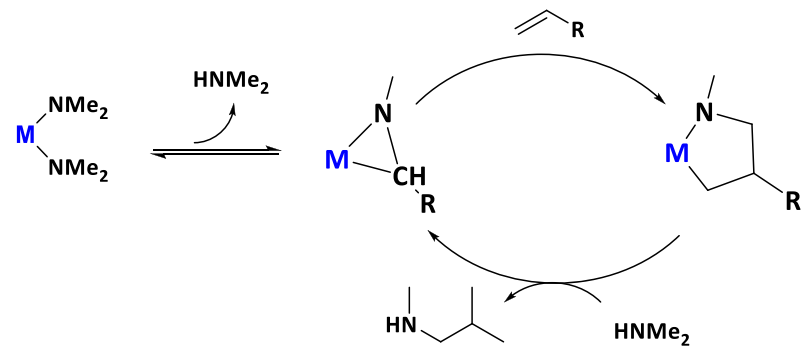

Figure 2. Catalytic mechanism of homogeneous hydroaminoalkylation. $3,4,7-15$

of an $\alpha$-amino $\mathrm{C}-\mathrm{H}$ moiety across an alkene double bond (Figure 1)..$^{2-4}$

This reaction is a new path for functionalizing simple amines, which are essential in the pharmaceutical, agrochemical, and fine chemical industries. ${ }^{5}$ In homogeneous
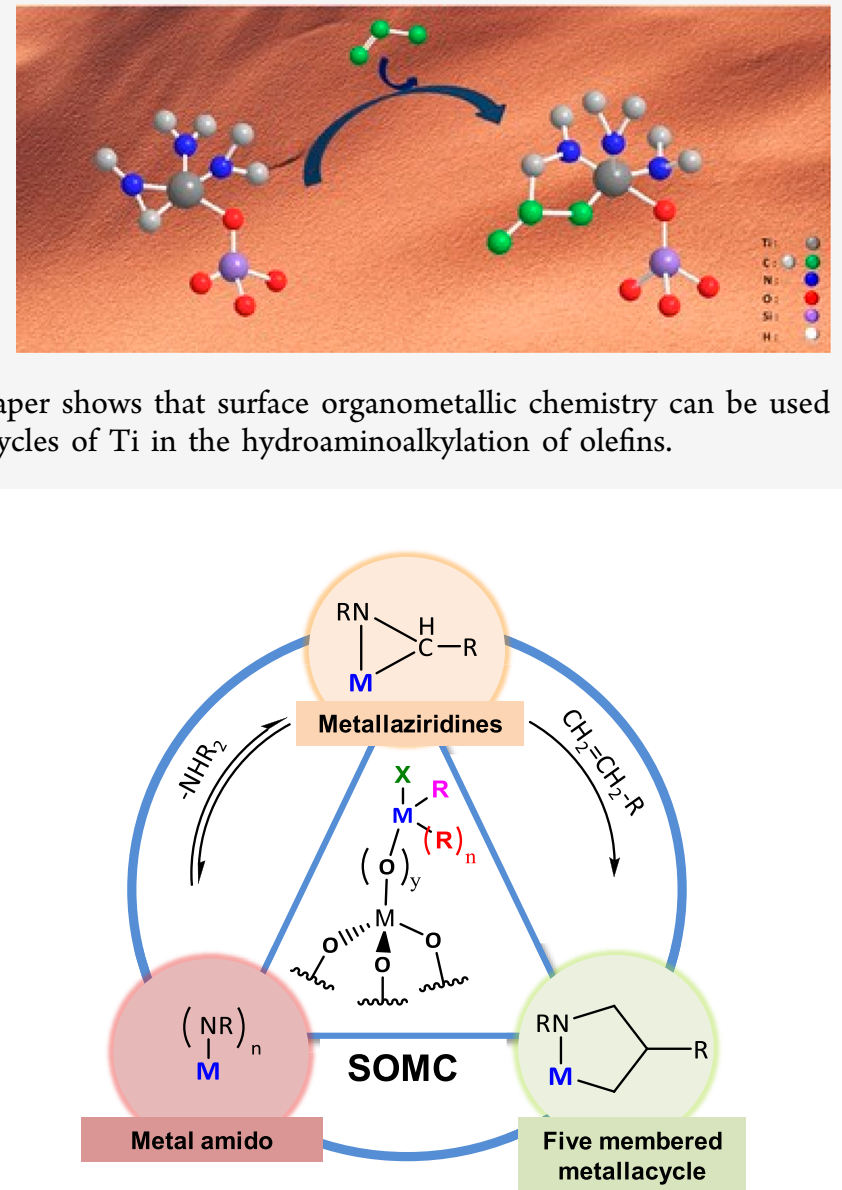

Figure 3. Expected surface three- and five-membered metallacycle key intermediates for hydroaminoalkylation.

Received: April 7, 2020 


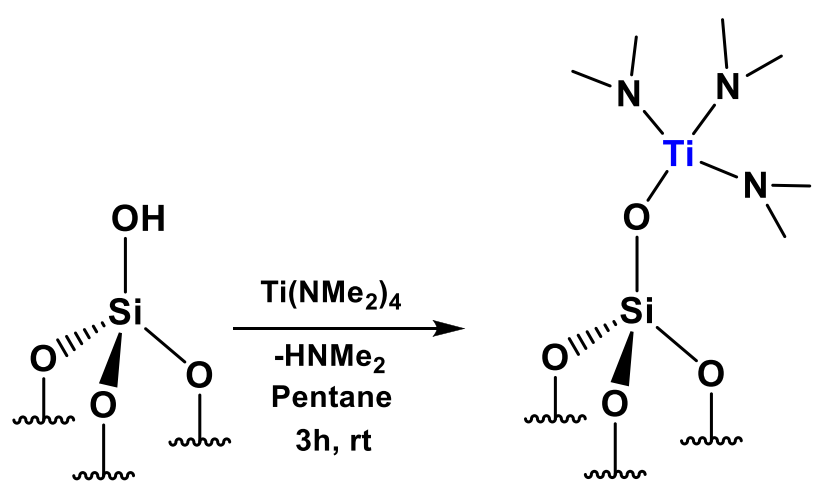

Figure 4. Titanium tris(amido) fragment immobilized on $\mathrm{SiO}_{2-700}$.

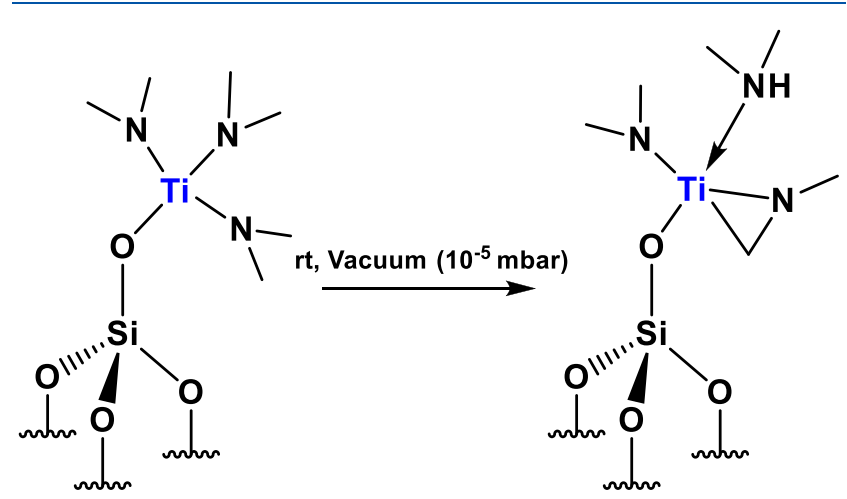

Figure 5. Titanaaziridine (1) formation at room temperature and under dynamic vacuum $\left(10^{-5} \mathrm{mbar}\right)$.

catalysis, the reaction mechanism was proposed and the fivemembered-ring formation was demonstrated under experimental conditions (X-ray) ${ }^{6}$ to occur by insertion of terminal alkene into the $\mathrm{M}-\mathrm{C}$ bond of a metallaaziridine (Figure 2). $3,4,7-16$

As is well-known, the objectives of surface organometallic chemistry (SOMC) are predicting (by rational approach) new reactions, improving existing ones, and understanding the mechanism, using the single-site concept (Figure 3). ${ }^{17-28}$

Therefore, in the present study, we have explored the possibility of grafting the homoleptic tetrakis(dimethylamido) complexes $\left[\mathrm{Ti}\left(\mathrm{NMe}_{2}\right)_{4}\right]$ on highly dehydroxylated silica $\left(\mathrm{SiO}_{2-700}\right)$, with the intent of drawing a full image of what was done previously in our group with the homoleptic zirconuim complex. ${ }^{29-31}$ The objective was to isolate, using SOMC concepts and tools, ${ }^{32-35}$ all or some of the elementary steps of the catalytic cycle of heterogeneous hydroaminoalkylation previously proposed in homogeneous catalysis. ${ }^{36-39}$

The reason to choose SOMC is as follows. By immobilization of surface organometallic fragments on surfaces, (1) it prevents bimolecular reactions and (2) it can isolate and fully characterize reaction intermediates.

We should notie here that the five-membered metallacycle was suggested in the case ofhydroaminoallylation, but it was in the case of $\mathrm{Zr}$ and with propene as the olefin. Obviously as frequently occurs with group IV metals, there is a strong similarity of mechanisms among all of these metals.

Consequently, with this objective in mind, an isolation of the surface $\left[(\equiv \mathrm{Si}-\mathrm{O}-) \mathrm{Ti}\left(-\mathrm{NMe}_{2}\right)_{3}\right]$ has been tested by reacting the homoleptic $\left[\mathrm{Ti}\left(\mathrm{NMe}_{2}\right)_{4}\right]$ complex with $\mathrm{SiO}_{2-700}$ (highly dehydroxylated silica treated at $700{ }^{\circ} \mathrm{C}$ ) (Figure 4).
Interestingly, the isolated species was a three-membered cycle (called a metallaziridine ${ }^{39-47}$ ) obtained at room temperature under vacuum (dynamic vacuum, $10^{-5} \mathrm{mbar}$ for $3 \mathrm{~h}$ ) (Figure 5) and this three-membered metallacycle was very well characterized by FTIR, elemental analysis, SS NMR, and DNP SENS. ${ }^{45,48}$

\section{THREE-MEMBERED-RING FRAGMENT: PREPARATION AND CHARACTERIZATION}

FTIR and elemental analysis have been carried out for the titanium tris(amido) complex. The obtained results were

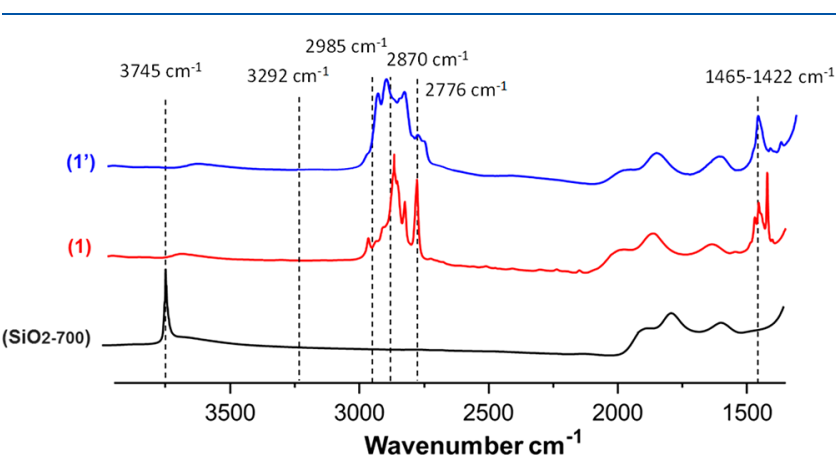

Figure 6. FTIR spectra of $\mathrm{SiO}_{2-700}$ (black), and the isolated metallacycles (1) $\left[(\equiv \mathrm{Si}-\mathrm{O}-) \mathrm{Ti}\left(\eta^{2}-\mathrm{MeNCH}_{2}\right)\left(\eta^{1}-\mathrm{NMe}_{2}\right)\left(\eta^{1}\right.\right.$ $\left.\left.\mathrm{HNMe}_{2}\right)\right]$ (red) and $\left(1^{\prime}\right)\left[(\equiv \mathrm{Si}-\mathrm{O}-) \mathrm{Ti}\left(\mathrm{HNMe}_{2}\right)\left(\eta^{2}-\mathrm{NMeCH}_{2} \mathrm{CH}-\right.\right.$ $\left.\left.\left(\mathrm{C}_{6} \mathrm{H}_{13}\right) \mathrm{CH}_{2}\right)\left(-\mathrm{NMe}_{2}\right)\right]$ (blue).

Table 1. Elemental Analysis for the Tris(amido) Complex 1

\begin{tabular}{lccc} 
& \multicolumn{3}{c}{ ratio } \\
\cline { 2 - 4 } & $\mathrm{N} / \mathrm{C}$ & $\mathrm{N} / \mathrm{M}$ & $\mathrm{C} / \mathrm{M}$ \\
complex 1 $( \pm 5 \%)$ & 0.5 & 3.1 & 5.7 \\
predicted for tris(amido) & $\mathbf{0 . 5}$ & 3 & 6 \\
\hline
\end{tabular}

consistent with the proposed structure of the surface complex $\left[(\equiv \mathrm{Si}-\mathrm{O}-) \mathrm{Ti}\left(\mathrm{NMe}_{2}\right)_{3}\right]$. The FTIR spectrum of the starting $\mathrm{SiO}_{2-700}$ shows an intense $\nu(\mathrm{O}-\mathrm{H})$ peak located at $3745 \mathrm{~cm}^{-1}$. This peak disappears after grafting of $\left[\mathrm{Ti}\left(\mathrm{NMe}_{2}\right)_{4}\right]$. A new range of signals appears for $\mathrm{C}-\mathrm{H}$ (stretching and bending). Intense bands are observed at $2970-2776 \mathrm{~cm}^{-1}(\nu(\mathrm{CH}))$ and weak bands at $1500-1400 \mathrm{~cm}^{-1}(\delta(\mathrm{CH}))$. In addition, no band was observed which could be ascribed to a $\mathrm{Si}-\mathrm{NMe}_{2}$ moiety. This absence of $\mathrm{Si}-\mathrm{NMe}_{2}$ means that there is no formation of doubly or triply bridged $\mathrm{Ti}$ as would occur by opening of a $\mathrm{Si}-\mathrm{O}-\mathrm{Si}$ bond (Figure 6, spectrum 1).

In addition, an elemental analysis of the tentative structure of the surface complex $\left[(\equiv \mathrm{Si}-\mathrm{O}-) \mathrm{Ti}\left(-\mathrm{NMe}_{2}\right)_{3}\right]$ shows ratios $( \pm 5 \%$ error $)$ consistent with the predicted values for the tris(amido) complex $\left[(\equiv \mathrm{Si}-\mathrm{O}-) \mathrm{Ti}\left(-\mathrm{NMe}_{2}\right)_{3}\right]$ (Table 1).

Nonetheless, the ${ }^{13} \mathrm{C}$ NMR and the ${ }^{1} \mathrm{H}$ NMR spectra are not consistent with the tentative structure $[(\equiv \mathrm{Si}-\mathrm{O}-) \mathrm{Ti}-$ $\left.\left(-\mathrm{NMe}_{2}\right)_{3}\right]$. Accordingly, the ${ }^{1} \mathrm{H}$ NMR spectrum of the compound obtained (Figure S4 in the Supporting Information) reveals a peak located at $2.5 \mathrm{ppm}$, assigned to the proton present in the dimethylamido ligands and a second peak at 1.6 ppm. The presence of these peaks is not consistent with the expected tris (amido) complex $\left[(\equiv \mathrm{Si}-\mathrm{O}-) \mathrm{Ti}\left(--\mathrm{NMe}_{2}\right)_{3}\right]$ that should show three equivalent dimethylamido ligands (one peak). Therefore, a different structure has to be well thought out: a metallaaziridine fragment, in which methylene 

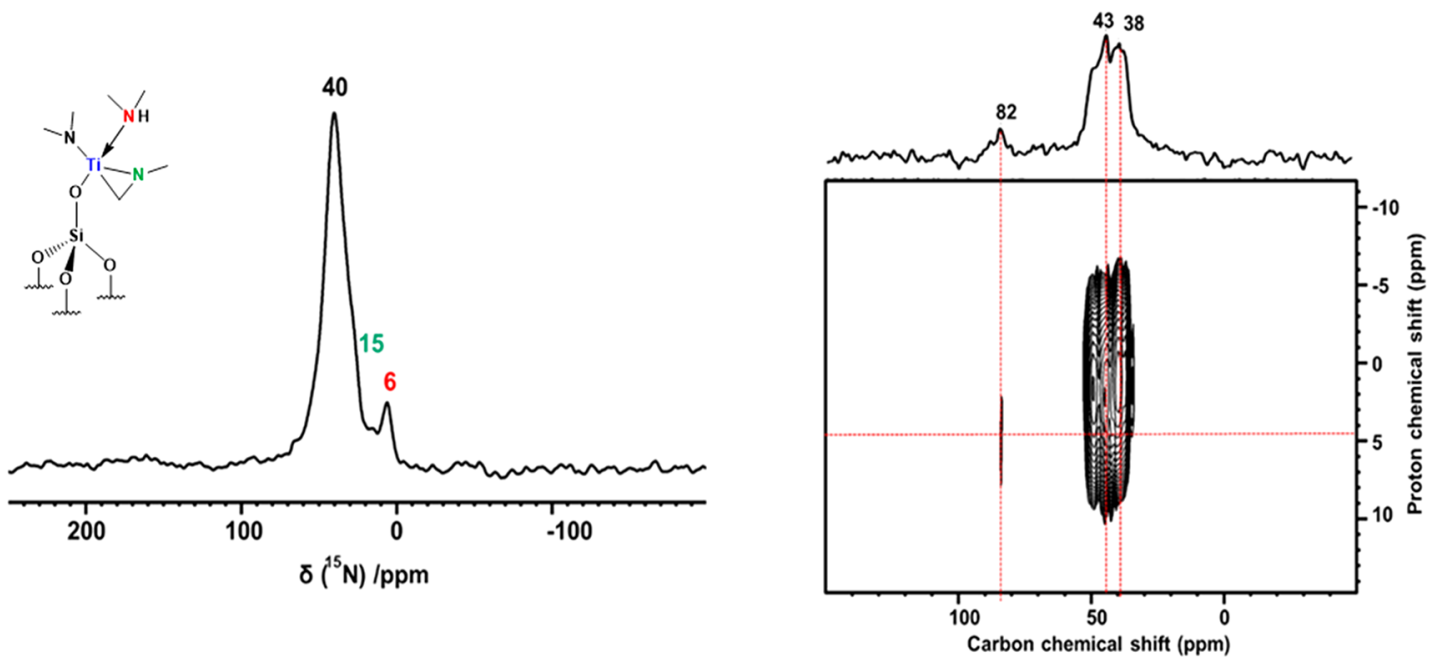

Figure 7. ${ }^{15} \mathrm{~N}$ MAS DNP SENS spectra (left) and $2 \mathrm{D}{ }^{1} \mathrm{H}-{ }^{13} \mathrm{C}$ HETCOR (heteronuclear correlation) NMR spectra (right) of $\left[(\equiv \mathrm{Si}-\mathrm{O}-) \mathrm{Ti}\left(\eta^{2}-\right.\right.$ $\left.\left.\mathrm{MeNCH}_{2}\right)\left(\eta^{1}-\mathrm{NMe}_{2}\right)\left(\eta^{1}-\mathrm{HNMe}_{2}\right)\right](\mathbf{1})$.

was directly coordinated to the titanium atom. Additionally, the ${ }^{13} \mathrm{C}$ NMR spectrum of the supported metal complex reveals three clearly identified signals: at $43 \mathrm{ppm}$ (br), at 38 ppm (low intensity), and a signal of much lower intensity at 82 ppm. Therefore, further advanced SS NMR experiments were carried out to confirm this hypothesis.

The HETCOR spectrum reveals the ${ }^{1} \mathrm{H}-{ }^{13} \mathrm{C}$ correlations (Figure 7). Clear correlations are seen between the methyl protons at $2.5 \mathrm{ppm}$ and the carbons at 38 and $43 \mathrm{ppm}$. Another more interesting correlation is observed between the signal at $82 \mathrm{ppm}^{39}$ and the proton at $4.6 \mathrm{ppm}$. Two-dimensional proton double- and triple-quantum (DQ, TQ) correlation experiments (Figure S4 in the Supporting Information) were performed to determine the number of protons attached to the same carbon and to differentiate between $\mathrm{CH}_{2}$ and $\mathrm{CH}_{3}$ groups. A strong autocorrelation peak observed for the proton at $2.5 \mathrm{ppm}$ in both DQ and TQ spectra is compatible with the assignment of this resonance to methyl protons. The proton resonance at 4.6 ppm does not appear in DQ and TQ spectra because of the low intensity of this peak.

The natural-abundance ${ }^{15} \mathrm{~N}$ DNP spectrum obtained for 1 (Figure 7) displays three resonances at 6, 15, and $41 \mathrm{ppm}$. Considering their relative abundance, we assign the intense signal shifted downfield at $41 \mathrm{ppm}$ to a $\sigma$-bonded $-\mathrm{NMe}_{2}$ ligand. The second peak at $15 \mathrm{ppm}$ is attributed to the $\mathrm{N}$ present in the aziridine fragment, and the weak upfield-shifted signal at $6 \mathrm{ppm}$ is compatible with a $\pi$-bonded $\mathrm{NH}\left(\mathrm{CH}_{3}\right)_{2}$ (ligand type L coordinated group).

\section{FIVE-MEMBERED-RING FRAGMENT: PREPARATION AND CHARACTERIZATION}

To continue our investigation on the mechanism of hydroaminoalkylation, we isolated the five-membered-ring (key intermediate $)$ complex $\left[(\equiv \mathrm{SiO}-) \mathrm{Ti}\left(\eta^{1}-\mathrm{HNMe}_{2}\right)\left(\eta^{2}-\right.\right.$ $\left.\left.\mathrm{NMeCH}_{2} \mathrm{CH}\left(\mathrm{C}_{6} \mathrm{H}_{13}\right) \mathrm{CH}_{2}\right)\left(-\mathrm{NMe}_{2}\right)\right]\left(\mathbf{1}^{\prime}\right)$ formed by insertion of 1 -octene in the $\mathrm{M}-\mathrm{C}$ bond of the metallaaziridine.

The titanaaziridine was treated with neat liquid 1-octene ( 1.5 equiv, $24 \mathrm{~h}$, and $165{ }^{\circ} \mathrm{C}$ ); the obtained product was washed with pentane and dried under vacuum $\left(10^{-5} \mathrm{mbar}\right)$ for 2-3 h (Figure 8). An FTIR spectrum of the obtained complex $\mathbf{1}^{\prime}$ shows an increase in the intensity of the $\nu(\mathrm{C}-\mathrm{H})$ bands $\left(2985-2776 \mathrm{~cm}^{-1}\right)$ that is expected by the insertion of the 1 -

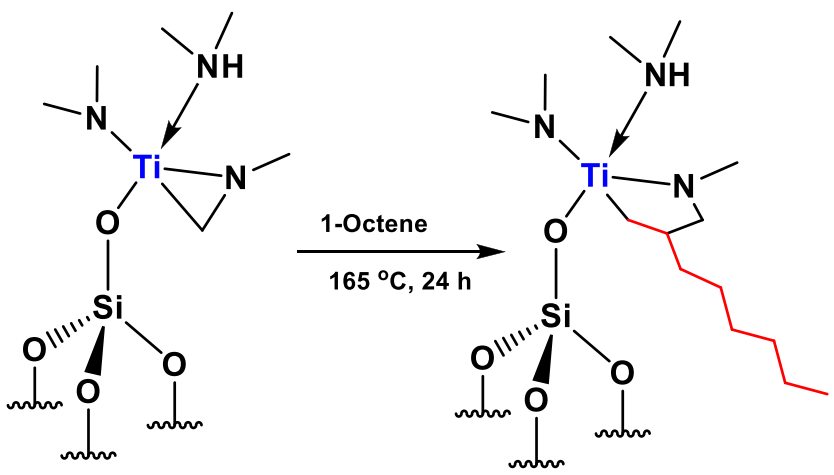

Figure 8. Five-membered metallacycle $\left(1^{\prime}\right)$ formation by insertion of 1-octene into surface titanaaziridine (1).

Table 2. Elemental Analysis for the Five-Membered Ring $\mathbf{1}^{\prime}$

\begin{tabular}{llll} 
& \multicolumn{3}{c}{ ratio } \\
\cline { 2 - 4 } & $\mathrm{N} / \mathrm{C}$ & $\mathrm{N} / \mathrm{M}$ & $\mathrm{C} / \mathrm{M}$ \\
complex 1' $( \pm 5 \%)$ & 0.2 & 2.8 & 13.2 \\
predicted for the five-membered metallacycle & $\mathbf{0 . 2 1}$ & 3 & $\mathbf{1 4}$ \\
\hline
\end{tabular}

octene in the titanaaziridine fragment (see Figure 6, spectrum $1^{\prime}$ ). The elemental analysis (Table 2) of complex $\mathbf{1}^{\prime}$ strongly confirms that one molecule of 1-octene has been incorporated in the metallaaziridine complex 1 very likely by simple 1,2insertion in which the long alkyl fragment is away from the metal for obvious steric reasons.

The ${ }^{1} \mathrm{H}$ SSNMR spectrum of the complex $\mathbf{1}^{\prime}$ exhibits a peak at $2.9 \mathrm{ppm}$ assigned to the $\mathrm{CH}_{2}$ of the five-membered ring next to the metal center. This $\mathrm{CH}_{2}$ peak overlaps with another $\mathrm{CH}_{2}$ signal at $2.4 \mathrm{ppm}$ in the five-membered ring. Two major signals, the first at $1.15 \mathrm{ppm}$ for $\mathrm{CH}_{2}$ and the second at 0.7 ppm for $\mathrm{CH}_{3}$, are present in the 1-octene tail. The $\mathrm{CH}_{2}$ and $\mathrm{CH}_{3}$ assignments were validated by the DQ and TQ correlations (Figure 9).

The 1.9 ppm peak assigned to the $\mathrm{CH}$ group in the fivemembered ring represents the more complex hydrocarbon motif around the titanium center; it appears as a very low intensity peak in the ${ }^{1} \mathrm{H}$ spectra logically without any autocorrelation in $\mathrm{DQ}$ or TQ frequencies. The ${ }^{13} \mathrm{C}$ SSNMR 


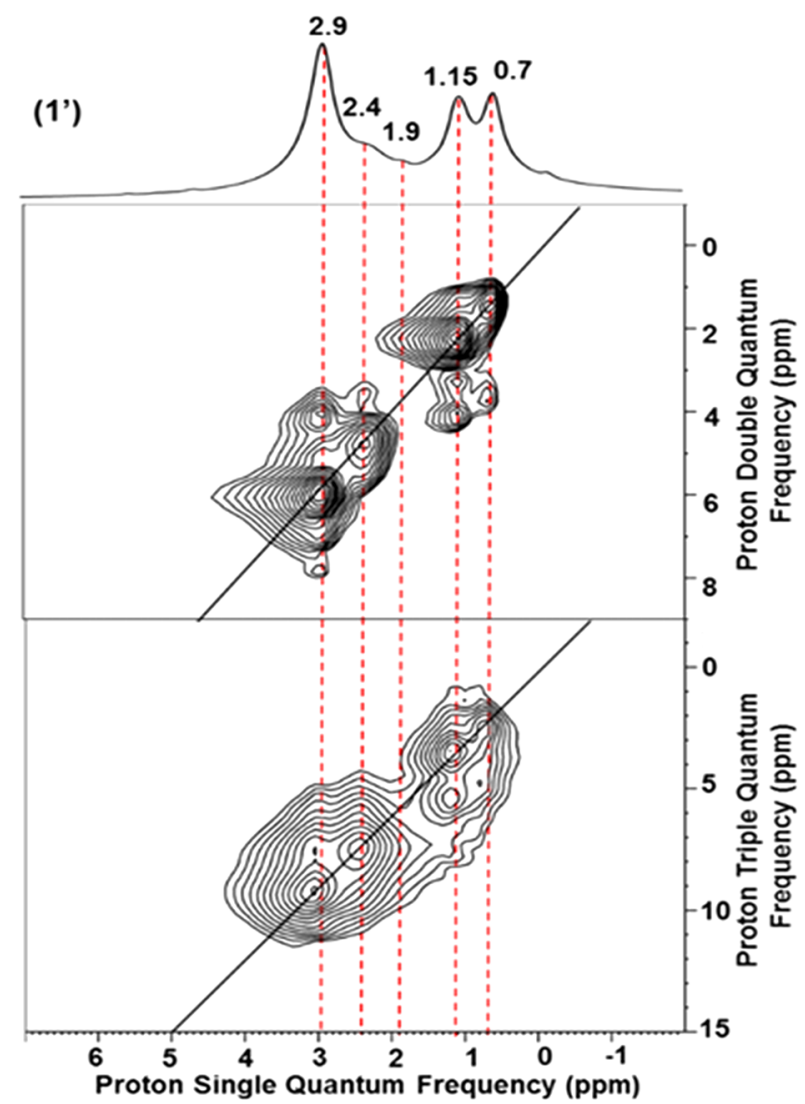

Figure 9. ${ }^{1} \mathrm{H}-{ }^{1} \mathrm{H}$ DQ spectra (top) and ${ }^{1} \mathrm{H}-{ }^{1} \mathrm{H}$ TQ spectra (bottom) for $\left[(\equiv \mathrm{Si}-\mathrm{O}-) \mathrm{Ti}-\left(\eta^{1}-\mathrm{HNMe}_{2}\right)\left[\eta^{2}-\mathrm{NMeCH}_{2}\left(\mathrm{C}_{6} \mathrm{H}_{13}\right)\right.\right.$ $\left.\left.\mathrm{CH}_{2}\right]\left(-\mathrm{NMe}_{2}\right)\right]\left(\mathbf{1}^{\prime}\right)$.

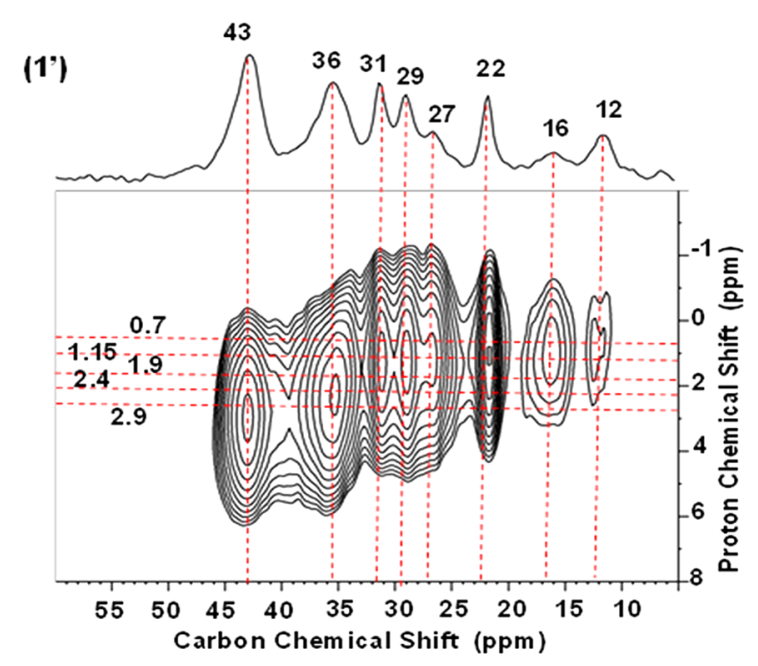

Figure 10. $2 \mathrm{D}{ }^{1} \mathrm{H}-{ }^{13} \mathrm{C}$ HETCOR NMR spectrum of the fivemembered-ring intermediate $\mathbf{1}^{\prime}$.

spectrum of this complex shows six major peaks at 12, 22, 29, 31,36 , and $43 \mathrm{ppm}$. The resonance at $36 \mathrm{ppm}$ is significantly intense in comparison to the others; this peak is assigned to the $\mathrm{CH}_{2}$ of the five-membered ring next to the titanium center. This interpretation is compatible with the multiple-quanta experimental spectra that reveal autocorrelations in doublequantum (DQ) and triple-quantum (TQ) frequencies for the signals at $2.4 \mathrm{ppm}$.

In addition, the $2 \mathrm{D}{ }^{1} \mathrm{H}-{ }^{13} \mathrm{C}$ HETCOR NMR spectrum (Figure 10) shows a correlation between the carbon peak at 36

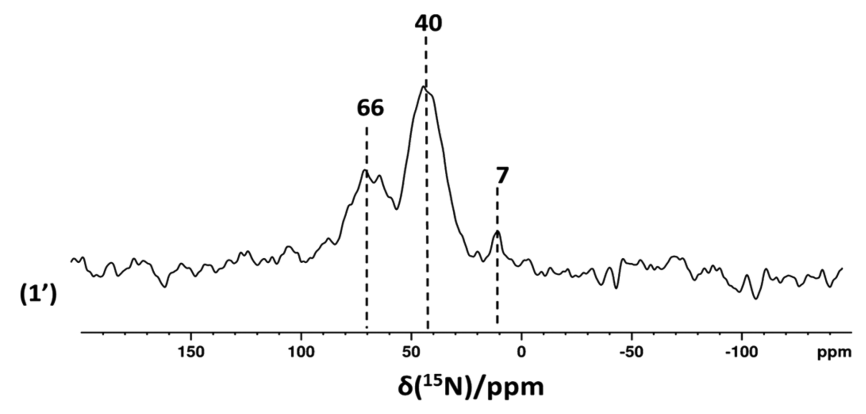

Figure 11. ${ }^{15} \mathrm{~N}$ MAS DNP SENS spectrum of $\left[(\equiv \mathrm{Si}-\mathrm{O}-) \mathrm{Ti}\left(\eta^{1}-\right.\right.$ $\left.\left.\mathrm{HNMe}_{2}\right)\left(\eta^{2}-\mathrm{NMeCH}_{2} \mathrm{CH}\left(\mathrm{C}_{6} \mathrm{H}_{13}\right) \mathrm{CH}_{2}\right)\left(-\mathrm{NMe}_{2}\right)\right]\left(\mathbf{1}^{\prime}\right)$.

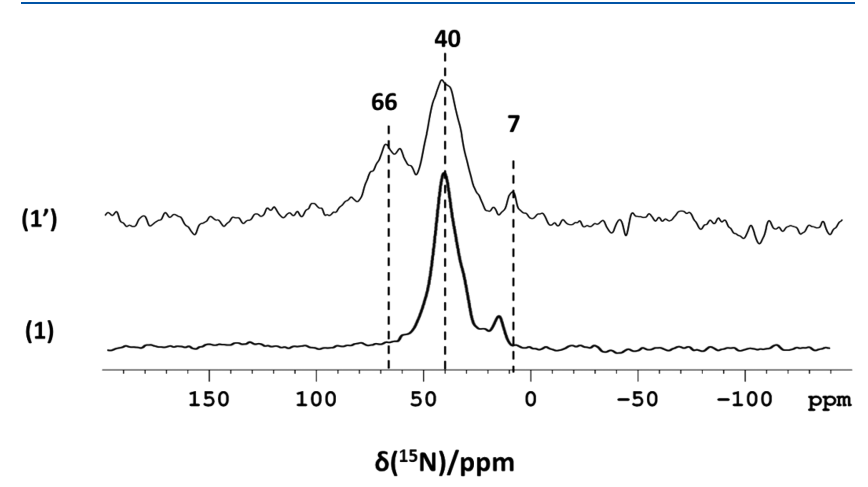

Figure 12. Stack plot of the spectra for the three-membered (1) and five-membered complexes $\left(\mathbf{1}^{\prime}\right)$.

ppm and the proton peak at $2.4 \mathrm{ppm}$. The signal at $22 \mathrm{ppm}$ for ${ }^{13} \mathrm{C}$ correlating with the $1.15 \mathrm{ppm}$ signal for ${ }^{1} \mathrm{H}$ is consistent with the $\mathrm{CH}_{2}$ fragments of the 1-octene queue.

A strong correlation is observed between the proton peak at $1.9 \mathrm{ppm}$ and the carbon peak at $31 \mathrm{ppm}$; this signal is attributed to the $\mathrm{CH}$ group.

The natural-abundance ${ }^{15} \mathrm{~N}$ SSNMR spectroscopy experiments were performed for $\mathbf{1}^{\prime}$ using the DNP-SENS technique (Figure 11). The obtained spectrum exhibits three peaks, centered at 7, 40, and $66 \mathrm{ppm}$ (Figure 12). The signals at 7 and $40 \mathrm{ppm}$ are tentatively related to $\pi$-bonded $\mathrm{NH}\left(\mathrm{CH}_{3}\right)_{2}$ and $\sigma$ bonded $-\mathrm{NMe}_{2}$, respectively. The new peak at $66 \mathrm{ppm}$ in the spectrum of $\mathbf{1}^{\prime}$ Figure 12 is assigned to the $\mathrm{N}$ atom involved in the five-membered ring.

\section{CATALYTIC TESTS}

Hydroaminoalkylation reaction studies were conducted with a mixture of 1-octene and a selected dialkylamine in $1 \mathrm{~mL}$ of

Table 3. Hydroaminoalkylation Catalytic Tests with Titanaazizidine (1) as a Catalyst ${ }^{a}$

\begin{tabular}{clc} 
entry & \multicolumn{1}{c}{ amine } & combined conversion (\%) \\
1 & $N$-methylaniline & 9.5 \\
2 & diethylamine & 23 \\
3 & dibutylamine & 15 \\
4 & N-ethylaniline & 0 \\
5 & diphenylamine & 0 \\
6 & dimethylamine & 0 \\
7 & ethylmethylamine & 0
\end{tabular}

${ }^{a}$ Conditions: $6 \mathrm{~mol} \%$ of catalyst complex $1,165^{\circ} \mathrm{C}, 1.5$ equiv of 1 octene, $1 \mathrm{~mL}$ of toluene, $48 \mathrm{~h}$. 


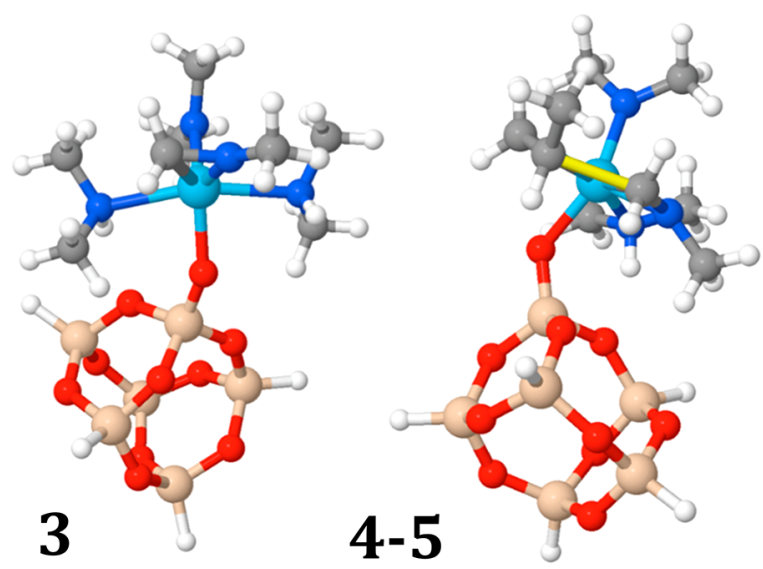

Figure 13. 3D representation of the aziridine complex 3 and the ratedetermining transition state 4-5 intermediate complex $2^{\prime}$.

toluene and the titanaaziridine complex catalyst $\mathbf{1}$ that was heated at $165{ }^{\circ} \mathrm{C}$ for $48 \mathrm{~h}$ in a vacuum-sealed ampule.

The screening was conducted using selected substrates such as dialkylamines (diethylamine and dibutylamine) and arylalkylamines ( $\mathrm{N}$-methylaniline and $\mathrm{N}$-ethylaniline) (Figures S5-S7 in the Supporting Information). All the runs and blanks were carried out under similar conditions. Branched and linear alkylation products detected as expected.

Catalysis with $\mathrm{N}$-methylaniline as the substrate (Table 3, entry 1) reached a combined conversion of $9.5 \%$. For entries 2 and 3 with dialkylamine substrates there were higher combined conversions of $23 \%$ and $15 \%$, respectively. However, in entries 4-7 there was no conversion observed, because the substrates are sterically hindered (Table 3 ).

\section{DENSITY FUNCTIONAL THEORY (DFT) CALCULATIONS}

All calculations were carried out with the Gaussian 09 suite of programs. Density functional theory (DFT) via the PBE1PBE functional (PBE0) was used for geometry optimizations. The SVP basis set was employed for the $\mathrm{Si}, \mathrm{C}, \mathrm{N}, \mathrm{O}$, and $\mathrm{H}$ atoms, and the SDD basis set was employed for Ti metal. Grimme D3 corrections were included in the energy evaluation. To obtain more accurate values, the reported energies have been obtained via single-point calculations using again the PBE0-D3 functional, by improving the main-group-atom basis set to the triple- $\zeta$ TZVP basis set.

Calculations have been performed using $\mathrm{Ti}$ as the metal and propene as the olefin. For the sake of simplicity, in the presence of $\mathrm{HNMe}_{2}$ we consider the tris(amido) amino complex 1 as the reference structure at $0 \mathrm{kcal} / \mathrm{mol}$ in energy. With 1 as the starting point, a fourth $\mathrm{HNMe}_{2}$ molecule coordinates to 1 , leading to 2 . The first reactive step is a $\beta-\mathrm{H}$ transfer between two amido ligands, leading to the metallaaziridine species 3, via transition state 2-3 and an energy barrier of $32.9 \mathrm{kcal} / \mathrm{mol}$. According to the calculations, 3 is located $14.1 \mathrm{kcal} / \mathrm{mol}$ above 1 ; therefore, the aziridine fragment is formed after the tris(amido) fragment is exposed to a high vacuum $\left(10^{-5}\right.$ mbar $)$ for $24 \mathrm{~h}$. The next step is the endergonic displacement of a dimethylamino ligand by propene, leading to $4,21.8 \mathrm{kcal} / \mathrm{mol}$ above 1 , followed by the rapid reaction of propene with the metallaaziridine moiety. Propene addition occurs via transition state $4-5$, at $34.1 \mathrm{kcal} /$ mol, and leads to intermediate 4 , only $4.4 \mathrm{kcal} / \mathrm{mol}$ above 1 . We calculated that 1,2-insertion of propene into the $\mathrm{Ti}-\mathrm{N}$ bond, leading to $\mathbf{5}$, is the favored regiochemistry, as it is favored by $4.4 \mathrm{kcal} / \mathrm{mol}$ over the transition state for 2,1insertion.

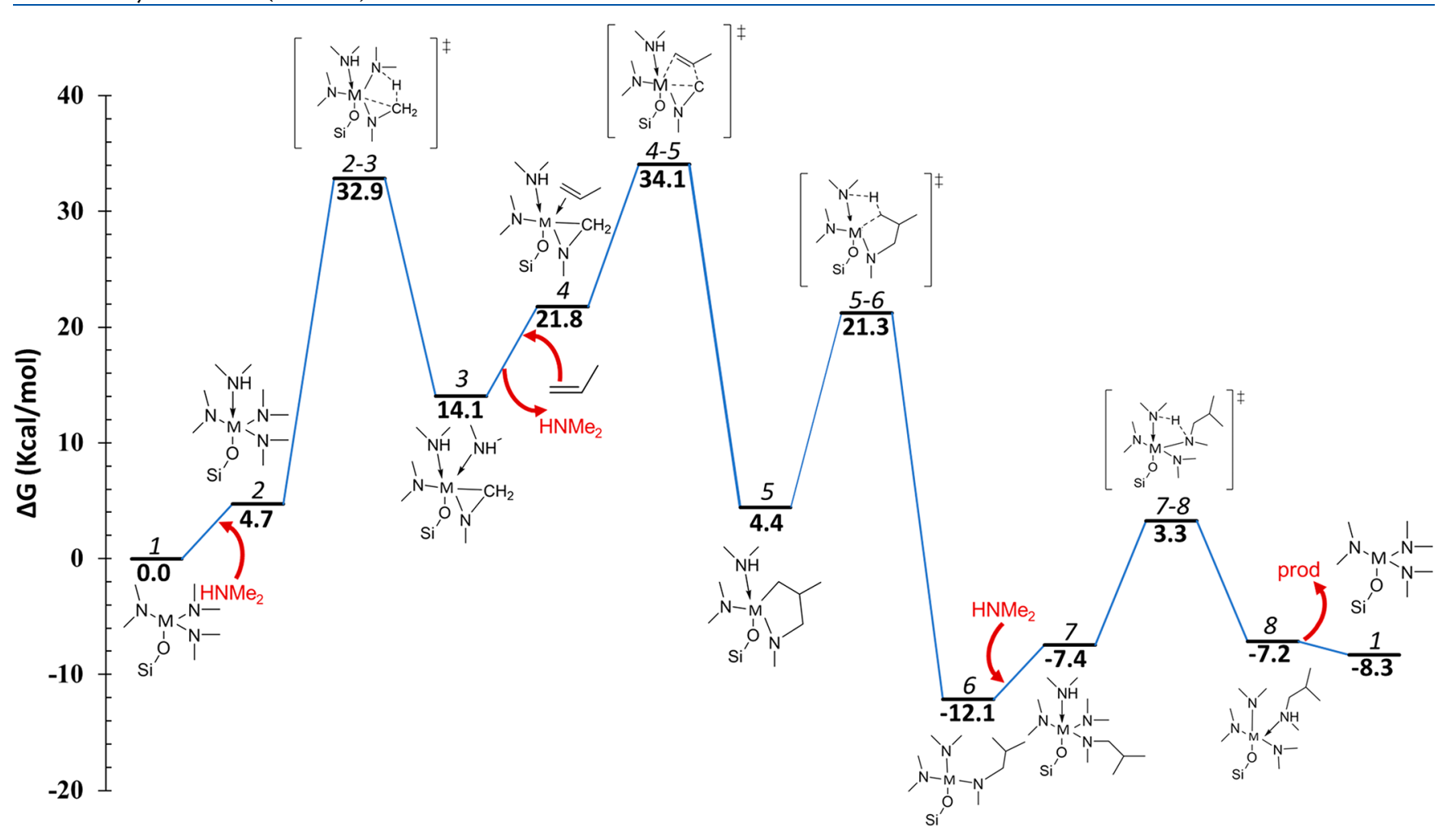

Figure 14. Energy profile for hydroaminoalkylation promoted by the Ti amido complex 1. 
The reaction evolves via $\mathrm{H}$ transfer from an amido ligand to the metallacycle moiety via transition state $5-6$, at $21.3 \mathrm{kcal} /$ mol, opening the metallacycle and leading to intermediate 5, $-12.1 \mathrm{kcal} / \mathrm{mol}$ below 1 . Coordination of an $\mathrm{HNMe}_{2}$ molecule, followed by $\mathrm{H}$ transfer from the coordinated dimethylamino to the $\mathrm{N}$ atom of the alkylated amido ligand, via transition state $\mathbf{7 - 8}$ at $3.3 \mathrm{kcal} / \mathrm{mol}$, leads to intermediate $\mathbf{8}$. The catalytic cycle is closed by displacement of the hydroaminoalkylated product by a dimethylamino ligand. The overall thermochemistry of the reaction is calculated to be $-8.3 \mathrm{kcal} / \mathrm{mol}$ with the adopted computational protocol. The overall energy span from 1 to $4-5,34.4 \mathrm{kcal} / \mathrm{mol}$, is consistent with the experimentally required long reaction times and high temperatures. The structures of the metallaaziridine complex 3 and the rate-determining transition state 4-5 are shown in Figure 13. In complex 3 the Ti assumes a distortedtrigonal-bipyramidal geometry, with the $\mathrm{Ti}-\mathrm{O}$, the $\mathrm{Ti}-$ amido, and the Ti-aziridine bonds in the equatorial plane and the two amino ligands along the axis. This disposition is preserved in the rate-determining transition state $4-5$, with propene replacing one of the amino ligands. The energy profile diagram is illustrated in Figure 14

\section{CONCLUSION}

To summarize, we succeeded in isolating two metallacycles involved in the hydroaminoalkylation of olefins: a titanaaziridine obtained by $\alpha$-H transfer between two adjacent $\sigma$-bonded $-\mathrm{N}\left(\mathrm{CH}_{3}\right)_{2}$ groups and the five-membered metallacycle obtained after insertion of 1-octene or any terminal alkene in the metal-carbon $(\mathrm{M}-\mathrm{C})$ bond of our well-characterized metallaaziridine fragment. It should be emphasized here that SOMC is unique in stabilizing such a metallacycle, especially the five-membered rings. Therefore, the reason for such a difference is very likely that there are no bimolecular reactions with surfaces, whereas in solution such bimolecular reactions easily occur.

\section{ASSOCIATED CONTENT}

\section{(s) Supporting Information}

The Supporting Information is available free of charge at https://pubs.acs.org/doi/10.1021/acs.organomet.0c00246.

FTIR, elemental analysis, NMR characterization, substrate analysis, and blank tests (PDF)

Cartesian coordinates for the calculate structures (XYZ)

\section{AUTHOR INFORMATION}

\section{Corresponding Authors}

Mohamad El Eter - Lebanese University, Faculty of sciences section III, Tripoli, Lebanon; Email: Mohamad_eleter@ hotmail.com

Luigi Cavallo - KAUST Catalysis Center, Division of Physical Sciences and Engineering, King Abdullah University of Science and Technology (KAUST), Thuwal 23955-6900, Kingdom of Saudi Arabia; 이이이.org/0000-0002-1398-338X; Email: Luigi.cavallo@kaust.edu.sa

Jean-Marie Basset - KAUST Catalysis Center, Division of Physical Sciences and Engineering, King Abdullah University of Science and Technology (KAUST), Thuwal 23955-6900, Kingdom of Saudi Arabia; (1) orcid.org/0000-0003-31668882; Email: jeanmarie.basset@kaust.edu.sa

\section{Authors}

Layal F. Yaacoub - KAUST Catalysis Center, Division of Physical Sciences and Engineering, King Abdullah University of Science and Technology (KAUST), Thuwal 23955-6900, Kingdom of Saudi Arabia; Lebanese University, Faculty of sciences section III, Tripoli, Lebanon

Maha A. Aljuhani - KAUST Catalysis Center, Division of Physical Sciences and Engineering, King Abdullah University of Science and Technology (KAUST), Thuwal 23955-6900, Kingdom of Saudi Arabia

Abdesslem Jedidi - Department of Chemistry, Faculty of Science, King Abdulaziz University, Jeddah 21589, Kingdom of Saudi Arabia; 이이이.org/0000-0003-4070-3299

Manal S. Al-Harbi - Department of Chemistry, Faculty of Science, King Abdulaziz University, Jeddah 21589, Kingdom of Saudi Arabia

Walid Al Maksoud - KAUST Catalysis Center, Division of Physical Sciences and Engineering, King Abdullah University of Science and Technology (KAUST), Thuwal 23955-6900, Kingdom of Saudi Arabia

Wiebke Wackerow - KAUST Catalysis Center, Division of Physical Sciences and Engineering, King Abdullah University of Science and Technology (KAUST), Thuwal 23955-6900, Kingdom of Saudi Arabia

Edy Abou-Hamad - King Abdullah University of Science and Technology (KAUST), Thuwal 23955-6900, Kingdom of Saudi Arabia

Jérémie D. A. Pelletier - KAUST Catalysis Center, Division of Physical Sciences and Engineering, King Abdullah University of Science and Technology (KAUST), Thuwal 23955-6900, Kingdom of Saudi Arabia

Complete contact information is available at:

https://pubs.acs.org/10.1021/acs.organomet.0c00246

\section{Author Contributions}

All authors have given approval to the final version of the manuscript.

\section{Notes}

The authors declare no competing financial interest.

\section{ACKNOWLEDGMENTS}

The King Abdullah University of Science and Technology (KAUST) supported the research. The authors acknowledge core lab at KAUST for their assistance. L.C. and A.J. are grateful to the KAUST Supercomputing Laboratory for the resources. A.J. thank High-Performance Computing Center (AZIZ supercomputer) for the support.

\section{REFERENCES}

(1) Clerici, M. G.; Maspero, F. Catalytic C-Alkylation of Secondary Amines with Alkenes. Synthesis 1980, 1980 (04), 305-306.

(2) Nugent, W. A.; Ovenall, D. W.; Holmes, S. J. Catalytic C-H activation in early transition-metal dialkylamides and alkoxides. Organometallics 1983, 2 (1), 161-2.

(3) Prochnow, I.; Zark, P.; Müller, T.; Doye, S. The Mechanism of the Titanium-Catalyzed Hydroaminoalkylation of Alkenes. Angew. Chem., Int. Ed. 2011, 50 (28), 6401-6405.

(4) Kubiak, R.; Prochnow, I.; Doye, S. Titanium-Catalyzed Hydroaminoalkylation of Alkenes by C-H Bond Activation at sp3 Centers in the $\alpha$-Position to a Nitrogen Atom. Angew. Chem., Int. Ed. 2009, 48 (6), 1153-1156. 
(5) Reznichenko, A. L.; Hultzsch, K. C. The Mechanism of Hydroaminoalkylation Catalyzed by Group 5 Metal Binaphtholate Complexes. J. Am. Chem. Soc. 2012, 134 (6), 3300-3311.

(6) Rosien, M.; Töben, I.; Schmidtmann, M.; Beckhaus, R.; Doye, S. Titanium-Catalyzed Hydroaminoalkylation of Ethylene. Chem. - Eur. J. 2020, 26 (10), 2138-2142.

(7) Herzon, S. B.; Hartwig, J. F. Hydroaminoalkylation of Unactivated Olefins with Dialkylamines. J. Am. Chem. Soc. 2008, 130 (45), 14940-14941.

(8) Prochnow, I.; Kubiak, R.; Frey, O. N.; Beckhaus, R.; Doye, S. Tetrabenzyltitanium: An Improved Catalyst for the Activation of sp3 C-H Bonds Adjacent to Nitrogen Atoms. ChemCatChem 2009, 1 (1), $162-172$.

(9) Kubiak, R.; Prochnow, I.; Doye, S. [Ind2TiMe2]: A Catalyst for the Hydroaminomethylation of Alkenes and Styrenes. Angew. Chem., Int. Ed. 2010, 49 (14), 2626-2629.

(10) Roesky, P. W. Catalytic Hydroaminoalkylation. Angew. Chem., Int. Ed. 2009, 48 (27), 4892-4894.

(11) Dörfler, J.; Preuß, T.; Brahms, C.; Scheuer, D.; Doye, S. Intermolecular hydroaminoalkylation of alkenes and dienes using a titanium mono(formamidinate) catalyst. Dalton Transactions 2015, 44 (27), 12149-12168.

(12) Dörfler, J.; Doye, S. Aminopyridinato Titanium Catalysts for the Hydroaminoalkylation of Alkenes and Styrenes. Angew. Chem., Int. Ed. 2013, 52 (6), 1806-1809.

(13) Schmitt, D. C.; Lee, J.; Dechert-Schmitt, A.-M. R.; Yamaguchi, E.; Krische, M. J. Ruthenium catalyzed hydroaminoalkylation of isoprene via transfer hydrogenation: byproduct-free prenylation of hydantoins. Chem. Commun. 2013, 49 (54), 6096-6098.

(14) Preuß, T.; Saak, W.; Doye, S. Titanium-Catalyzed Intermolecular Hydroaminoalkylation of Conjugated Dienes. Chem. - Eur. J. 2013, 19 (12), 3833-3837.

(15) Chong, E.; Garcia, P.; Schafer, L. L. Hydroaminoalkylation: Early-Transition-Metal-Catalyzed $\alpha$-Alkylation of Amines. Synthesis 2014, 46 (21), 2884-2896.

(16) Bürger, H.; Kluess, C. TITANIUM-NITROGEN COMPOUNDS. XXIV. BENZYL-AND TRIMETHYLSILYLMETHYLTITANIUM AMIDES-PREPARATION, PROPERTIES AND THERMOLYSIS. Chem. Informationsdienst 1976, 7 (23), no-no.

(17) Copéret, C.; Chabanas, M.; Petroff Saint-Arroman, R.; Basset, J.-M. Homogeneous and Heterogeneous Catalysis: Bridging the Gap through Surface Organometallic Chemistry. Angew. Chem., Int. Ed. 2003, 42 (2), 156-181.

(18) Samantaray, M. K.; Pump, E.; Bendjeriou-Sedjerari, A.; D’Elia, V.; Pelletier, J. D.; Guidotti, M.; Psaro, R.; Basset, J.-M. Surface organometallic chemistry in heterogeneous catalysis. Chem. Soc. Rev. 2018, 47 (22), 8403-8437.

(19) Beaudoin, M.; Scott, S. L. Spontaneous Evolution of SilicaSupported Ti Amide Fragments to Imine and Imido Complexes. Organometallics 2001, 20 (2), 237-239.

(20) Basset, J. M.; Ugo, R. On the Origins and Development of "Surface Organometallic Chemistry. Modern Surface Organometallic Chemistry 2009, 1-21.

(21) Pelletier, J. D. A.; Basset, J.-M. Catalysis by Design: WellDefined Single-Site Heterogeneous Catalysts. Acc. Chem. Res. 2016, 49 (4), 664-677.

(22) Saint-Arroman, R. P.; Chabanas, M.; Baudouin, A.; Copéret, C.; Basset, J.-M.; Lesage, A.; Emsley, L. Characterization of Surface Organometallic Complexes Using High Resolution 2D Solid-State NMR Spectroscopy. Application to the Full Characterization of a Silica Supported Metal Carbyne: : $\mathrm{SiO}-\mathrm{Mo}(: \mathrm{C}-\mathrm{Bu}-\mathrm{t})(\mathrm{CH} 2-\mathrm{Bu}-\mathrm{t}) 2$. J. Am. Chem. Soc. 2001, 123 (16), 3820-3821.

(23) Lefebvre, F.; Candy, J. P.; Santini, C. C.; Basset, J. M. Surface organometallic chemistry on metals. Application to chemicals and fine chemicals. Top. Catal. 1997, 4 (3), 211-216.

(24) Basset, J.-M.; Gates, B. C.; Candy, J.-P.; Choplin, A.; Leconte, M.; Quignard, F.; Santini, C. Surface organometallic chemistry: molecular approaches to surface catalysis; Springer Science \& Business Media: 2012; Vol. 231.
(25) Basset, J. M.; Candy, J. P.; Choplin, A.; Santini, C.; Theolier, A. Some recent aspects of surface organometallic chemistry. Catal. Today 1989, 6 (1), 1-26.

(26) Basset, J. M.; Choplin, A. Surface organometallic chemistry: A new approach to heterogeneous Catal.ysis ? J. Mol. Catal. 1983, 21 (1), 95-108.

(27) Lefort, L.; Chabanas, M.; Maury, O.; Meunier, D.; Copéret, C.; Thivolle-Cazat, J.; Basset, J.-M. Versatility of silica used as a ligand: effect of thermal treatments of silica on the nature of silica-supported alkyl tantalum species. J. Organomet. Chem. 2000, 593-594, 96-100.

(28) Candy, J.-P.; Lecuyer, C.; Quignard, F.; Choplin, A.; Scott, S. L.; Basset, J.-M.; Niccolai, G. P.; Santini, C. C New J. Chem. 1994, 18, $115-122$.

(29) Hamzaoui, B.; Pelletier, J. D.; El Eter, M.; Chen, Y.; AbouHamad, E.; Basset, J. M. J. A. S. Adv. Synth. Catal. 2015, 357 (14-15), $3148-3154$.

(30) Hamzaoui, B. Well-defined silica-supported zirconium-imido complexes mediated heterogeneous imine metathesis. Chem. Commun. 2016, 52, 4617.

(31) Eter, M. E.; Hamzaoui, B.; Abou-Hamad, E.; Pelletier, J. D. A.; Basset, J.-M. Well-defined azazirconacyclopropane complexes supported on silica structurally determined by $2 \mathrm{D}$ NMR comparative elucidation. Chem. Commun. 2013, 49 (41), 4616-4618.

(32) Aljuhani, M. A.; Zhang, Z.; Barman, S.; El Eter, M.; Failvene, L.; Ould-Chikh, S.; Guan, E.; Abou-Hamad, E.; Emwas, A.-H.; Pelletier, J. D. A.; Gates, B. C.; Cavallo, L.; Basset, J.-M. Mechanistic Study of Hydroamination of Alkyne through Tantalum-Based SilicaSupported Surface Species. ACS Catal. 2019, 9 (9), 8719-8725.

(33) Samantaray, M. K.; D’Elia, V.; Pump, E.; Falivene, L.; Harb, M.; Ould Chikh, S.; Cavallo, L.; Basset, J.-M. The Comparison between Single Atom Catalysis and Surface Organometallic Catalysis. Chem. Rev. 2020, 120 (2), 734-813.

(34) Hamzaoui, B.; Eter, M. E.; Abou-hamad, E.; Chen, Y.; Pelletier, J. D.; Basset, J. M. Inside Back Cover: Well-Defined Single-Site Monohydride Silica-Supported Zirconium from Azazirconacyclopropane (Chem. Eur. J. 11/2015). Chem. - Eur. J. 2015, 21 (11), 44674467.

(35) Scott, S. L.; Basset, J.-m.; Niccolai, G. P.; Santini, C. C.; Candy, J.-p.; Lecuyer, C.; Quignard, F.; Choplin, A. Surface organometallic chemistry: a molecular approach to surface catalysis; Springer Netherlands: 1993.

(36) Hamzaoui, B.; Pelletier, J. D. A.; El Eter, M.; Chen, Y.; AbouHamad, E.; Basset, J.-M. Isolation and Characterization of WellDefined Silica-Supported Azametallacyclopentane: A Key Intermediate in Catalytic Hydroaminoalkylation Reactions. Adv. Synth. Catal. 2015, 357 (14-15), 3148-3154.

(37) Hannedouche, J.; Schulz, E. Hydroamination and Hydroaminoalkylation of Alkenes by Group 3-5 Elements: Recent Developments and Comparison with Late Transition Metals. Organometallics 2018, 37 (23), 4313-4326.

(38) Bielefeld, J.; Doye, S. Dimethylamine as a Substrate in Hydroaminoalkylation Reactions. Angew. Chem., Int. Ed. 2017, 56 (47), 15155-15158.

(39) Buchwald, S. L.; Watson, B. T.; Wannamaker, M. W.; Dewan, J. C. Zirconocene complexes of imines. General synthesis, structure, reactivity, and in situ generation to prepare geometrically pure allylic amines. J. Am. Chem. Soc. 1989, 111 (12), 4486-4494.

(40) Mindiola, D. J.; Cummins, C. C. Probing the Niobium Metallaaziridine Functionality. Organometallics 2001, 20 (17), 36263628.

(41) Aljuhani, M. A.; Barman, S.; Abou-Hamad, E.; Gurinov, A.; Ould-Chikh, S.; Guan, E.; Jedidi, A.; Cavallo, L.; Gates, B. C.; Pelletier, J. D. A.; Basset, J.-M. Imine Metathesis Catalyzed by a SilicaSupported Hafnium Imido Complex. ACS Catal. 2018, 8 (10), 94409446.

(42) El Eter, M.; Hamzaoui, B.; Abou-Hamad, E.; Pelletier, J. D.; Basset, J.-M. Well-defined azazirconacyclopropane complexes supported on silica structurally determined by $2 \mathrm{D}$ NMR comparative elucidation. Chem. Commun. 2013, 49 (41), 4616-4618. 
(43) Bazinet, P.; Yap, G. P. A.; Richeson, D. S. Metallaaziridine Complexes of Tantalum Derived from 1,8-Bis(isopropylamino)naphthalene via $\beta$-H Activation. Organometallics 2001, 20 (20), 4129-4131.

(44) Lauzon, J. M. P.; Schafer, L. L. Tantallaaziridines: from synthesis to catalytic applications. Dalton Transactions 2012, 41 (38), $11539-11550$.

(45) Hamzaoui, B.; Pelletier, J. D. A.; Abou-Hamad, E.; Chen, Y.; El Eter, M.; Chermak, E.; Cavallo, L.; Basset, J.-M. Solid-State NMR and DFT Studies on the Formation of Well-Defined Silica-Supported Tantallaaziridines: From Synthesis to Catalytic Application. Chem. Eur. J. 2016, 22 (9), 3000-3008.

(46) Manßen, M.; Lauterbach, N.; Dörfler, J.; Schmidtmann, M.; Saak, W.; Doye, S.; Beckhaus, R. Efficient access to titanaaziridines by $\mathrm{C}-\mathrm{H}$ activation of $\mathrm{N}$-methylanilines at ambient temperature. Angew. Chem., Int. Ed. 2015, 54 (14), 4383-4387.

(47) Buchwald, S. L.; Watson, B. T.; Wannamaker, M. W.; Dewan, J. C. J. Am. Chem. Soc. 1989, 111 (12), 4486-4494.

(48) Blanc, F.; Basset, J.-M.; Copéret, C.; Sinha, A.; Tonzetich, Z. J.; Schrock, R. R.; Solans-Monfort, X.; Clot, E.; Eisenstein, O.; Lesage, A.; Emsley, L. Dynamics of Silica-Supported Catalysts Determined by Combining Solid-State NMR Spectroscopy and DFT Calculations. J. Am. Chem. Soc. 2008, 130 (18), 5886-5900. 